\title{
Associations of eating behaviours, fast food purchasing and availability with BMI-for-age z-score among adolescents in Labuan, Malaysia
}

\author{
Ho Shu Fen ${ }^{1}$, Chin Yit Siew ${ }^{1,2^{*}}$, Abdul Rashid Bin Mohamed Shariff ${ }^{3,4}$ \& Lim \\ Poh Ying 5 \\ ${ }^{1}$ Department of Nutrition, Faculty of Medicine and Health Sciences, Universiti Putra \\ Malaysia, Selangor, Malaysia; ${ }^{2}$ Research Centre of Excellence, Nutrition and Non- \\ Communicable Diseases, Faculty of Medicine and Health Sciences, Universiti Putra \\ Malaysia, Malaysia; ${ }^{3}$ Department of Biological \& Agricultural Engineering, Faculty of \\ Engineering, Universiti Putra Malaysia; ${ }^{4}$ Institution of Geospatial and Remote Sensing \\ Malaysia (IGRSM); ${ }^{5}$ Department of Community Health, Faculty of Medicine and \\ Health Sciences, Universiti Putra Malaysia
}

\begin{abstract}
Introduction: A cross-sectional study was conducted to determine the associations of socio-demographic factors, eating behaviours, fast food purchasing by parents for family meals, and availability of neighbourhood fast-food outlets with BMI-for-age z-score (BAZ) among adolescents. Methods: Through multi-stage stratified cluster sampling method, a total of 420 adolescents from five selected public secondary schools participated in the current study. Data on socio-demographic factors, eating behaviours, and parent's purchases of fast food were obtained through selfadministered questionnaires. The availability of fast-food outlets was assessed using Geographic Information System (GIS). Body weight and height of the adolescents were measured. Results: The prevalence of overweight, obesity, thinness and severe thinness among adolescents in the present study were $17.6 \%, 15.5 \%$, $3.1 \%$ and $0.7 \%$, respectively. The current findings showed that a higher monthly household income $\left(r_{\mathrm{s}}=0.12, p=0.02\right)$ and less purchases of fast food by parents for family meals $\left(r_{s}=-0.11, p=0.03\right)$ were significantly associated with higher BAZ of the adolescents. However, there were no significant associations between eating outside of home, eating at fast-food restaurants, buying delivery fast food, and availability of neighbourhood fast-food outlets with BAZ. Multiple linear regression showed that less purchases of fast food by parents for family meals significantly contributed towards higher BAZ ( $\beta=-0.25, p=0.02)$. Conclusion: A higher household income and less fast food purchasing by parents were associated with higher BAZ. Fast food purchasing of adolescents were not associated with BAZ. Therefore, an appropriate obesity intervention programme should focus on adolescents and their parents from middle- and high-income households in Labuan.
\end{abstract}

Keywords: Obesity, adolescents, household income, fast-food, GIS

\section{INTRODUCTION}

Obesity is a global public health problem. Obesity in adolescents affects their physical health including insulin resistance, pre-diabetes, metabolic syndrome, dyslipidaemia, hypertension, asthma, skin problem, and impaired

\footnotetext{
*Corresponding author: Chin Yit Siew Department of Nutrition, Faculty of Medicine and Health Sciences, Universiti Putra Malaysia Tel: (6)03-97692680; E-mail: chinys@upm.edu.my doi: https://doi.org/10.31246/mjn-2020-0026
} 
peak bone mass (Atay \& Bereket, 2016). Obese adolescents are more likely to stay obese in adulthood (Sahoo et al., 2015). The World Health Organization (WHO) reported that over 340 million children aged 5 to 19 years were overweight or obese in the year 2016 (WHO, 2017). The number of obese children and adolescents increased more than ten times higher from 1975 to 2016 (NCD Risk Factor Collaboration, 2017). The prevalence of overweight and obesity among adolescents in low and middle income Asian countries, including Malaysia, are on the rise (Atay \& Bereket, 2016; IPH, 2013; IPH, 2017). The Malaysian School-Based Nutrition Survey (MSNS) in the year 2012 reported that Sabah and Labuan had the lowest prevalence of overweight and obesity $(20.9 \%)$ compared to other states in Malaysia (IPH, 2013). Five years later, the National Health and Morbidity Survey (NHMS) conducted among adolescents aged 10 to 17 years in the Federal Territory of Labuan (Labuan) reported that the prevalence of overweight and obesity (33.7\%) was the highest in Malaysia (IPH, 2017). The prevalence of thinness among adolescents aged 10 to 17 years in Labuan reported in the years 2012 and 2017 were $4.5 \%$ and $4.7 \%$, respectively, which was the lowest compared to other states in Malaysia (IPH, 2013; IPH 2017). The drastic increase in the prevalence of overweight and obesity in Labuan warrants the urgent need to further study about the body weight status of adolescents in that city. To date, studies to determine the factors associated with body weight status among adolescents in Labuan are scarce.

Unhealthy eating behaviours such as decreased consumption of vegetables, fruits and milk, and increased consumption of high fat, high sugar foods, and fast foods, increase the risk of chronic health problems (Braithwaite et al., 2014). A previous qualitative study indicated that Malaysian adolescents had the knowledge of healthy eating; however, there were barriers for them to practise healthy eating, including lack of healthy foods available at schools and at home, as well as being attracted to the taste and characteristics of unhealthy foods (Sharifah Intan Zainun et al. 2020). Besides, a previous study by Fara Wahida et al. (2015) reported that self-efficacy for healthy eating and availability of healthy foods were positively associated with the diet quality of adolescents in Kuala Lumpur. A previous study has shown that frequent consumption of fast foods was associated with overweight and obesity among adolescents (Braithwaite et al., 2014). Furthermore, parent's purchase of fast foods has reduced the benefits of having healthy family meals at home such as lowering the risk of overweight and obesity among adolescents (Boutelle et al., 2007). In contrast, a few previous studies indicated that the frequency of eating fast foods had no significant association with body weight status in adolescents (IPH, 2013). This shows that there are mixed results found in the association between consumption of fast foods and body weight status among adolescents. Thus, eating behaviour is one of the important factors that should be determined in the study of obesity among adolescents.

In addition, studies on the association between built environment and adolescence obesity are increasing in the western countries, and such evidence is needed for developing strategies to combat obesity, especially in promoting and constructing healthier environments (Lytle \& Sokol, 2017). The availability of fast-food outlets nearby residences or schools were reported to be associated with an increased likelihood of purchasing fast foods ( $\mathrm{He}$ et al., 2012), which further increased the 
risk of overweight and obesity among adolescents (Virtanen et al., 2015). The Geographic Information System (GIS) method was widely used in public health in the western countries between the years 2007 and 2015 to measure food environment for addressing health needs and improving the built environment (Lytle \& Sokol, 2017). To date, there is limited published study on the food environment in Malaysia using GIS. Recently, Kee et al. (2019) reported the association between availability of fastfood outlets with the risk of overweight using GIS in West Malaysia, but did not include East Malaysia (Sabah, Sarawak and Labuan). Little is known on the association between built environment and body weight status among adolescents in Labuan. The purpose of the present study was to determine the prevalence of overweight and obesity, and to determine the associations of sociodemographic factors, eating behaviours, parent's purchases of fast food for family meals, and availability of neighbourhood fast-food outlets using GIS with body mass index-for-age $z$-score (BAZ) among adolescents in Labuan, Malaysia.

\section{MATERIALS AND METHODS}

A cross-sectional study was conducted in Labuan, Malaysia. The population of the current study were lower (Form 1 \& Form 2) and upper (Form 4) secondary school students. The estimated population for those aged 10 to 19 years in Labuan was 15400 in the year 2016 (DOSM, 2017). Based on Aday and Cornelius's (2006) calculation for prevalence study, the appropriate number of samples to represent the adolescents in the current study was 301 . The sample size was adjusted for design effect of 1.3 and non-response rate of $20 \%$. Hence, $>480$ respondents were needed in the present study.
A multi-stage stratified cluster sampling design was used in the current study. In particular, a list of national secondary schools in Labuan was obtained from the State Education Department of Labuan Federal Territory. At the first stage of sampling, the school locations were stratified into urban and rural, based on the administration of Labuan Corporation. Urban schools were located in the Labuan town area, while rural schools were located in villages (kampung). Two schools from urban and three schools from rural were selected randomly using probability proportionate to size in the current study (Aday \& Cornelius, 2006). At the second stage of sampling, classes in each selected school were randomly selected through systematic random sampling. All students from the selected classes were invited to participate in this study using cluster sampling method. While a total of 481 respondents were recruited, 437 students and their parents agreed to participate in the current study.

Ethical approval was obtained from the Ethics Committee for Research Involving Human Subjects Universiti Putra Malaysia [Ref: UPM/TNCPI/ RMC/ 1.4.18.2 (JKEUPM)]. Prior to data collection, permission to conduct the study was obtained from the Ministry of Education Malaysia and the State Education Department of Labuan Federal Territory. Permissions were also obtained from the respective principals of each school. Students' and parents' information sheets and consent forms were distributed to the respondents a week before data collection. Written informed consents of the students and their parents were obtained during the study.

\section{Data collection}

Data collection was carried out for two months, starting from August till 
September 2018, using student- and parent-administered questionnaires. Anthropometric measurements were assessed by the researcher and trained enumerators. At the beginning of data collection, the adolescents were briefed on the student-administered questionnaire and parent-administered questionnaire by the researchers. Adolescents filled in the student-administered questionnaire in school and the researchers collected the questionnaire on the same day to ensure that they were filled in individually, while parent-administered questionnaire required the adolescents to take it home for their parents or guardians to fill in and was collected by the researchers after completion.

\section{Anthropometry measurements}

Body weight of the respondent was measured by using TANITA Digital Weighing Scale THD-304 (TANITA Corporation, USA), while height was measured by using Charder HM202P Stadiometer. Body weight and height of the adolescents were measured by the researchers and trained enumerators using standard procedures. The enumerators were trained before data collection. The adolescent was requested to take off his or her shoes before measuring body weight and height. Each measurement was measured twice with weight recorded to the nearest $0.1 \mathrm{~kg}$ and height recorded to the nearest $0.1 \mathrm{~cm}$. A mean of the two measurements was used in data analysis. To ensure accuracy, the digital scale and stadiometer were routinely calibrated. BAZ was calculated by using the AnthroPlus software v1.0.4 (WHO, 2009). Body weight status classification was done using age- and sex-specific cut-offs based on the WHO Growth Reference 2007, which classifies overweight as having $z$-score $>+1$ standard deviation (SD), obesity as having $z$-score $>+2 \mathrm{SD}$, thinness as having $z$-score -2SD - $\leq-3 S D$, and severe thinness as having $z$-score $<-3 \mathrm{SD}$ (WHO, 2007).

\section{Socio-demographic characteristics}

Information including sex, age and ethnicity were obtained from the studentadministered questionnaire, while other information such as monthly household income and parent's education level was obtained from the parent-administered questionnaire.

\section{Eating behaviours}

Eating behaviours of the adolescents was assessed using the partial Malayversion Eating Behaviours Questionnaire (EBQ) (Chin \& Nasir, 2009). Frequency of eating food outside of home (e.g. hawker centres, coffee shops, or food stalls), eating food at western fast-food restaurants (e.g. KFC, McDonald's, or Marrybrown), and purchase of takeaway or delivery food from western fast-food restaurants were assessed. All items were rated based on a frequency scale, ranging from "never/less than one week" to "7 days/week".

\section{Parent's purchases of fast food for family meals}

Purchases of fast food for family meals was assessed by asking the parent "In the past week, how many times was a family meal purchased from a fastfood restaurant, and eaten either at the restaurant or at home?". Parent's purchases of fast food for family meals was used in the Project Families and Eating and Activity in Teens (F-EAT) Survey (Boutelle et al., 2007). The item was made on a 5-point Likert scale ranging from one point to five points. Response options included "never", "1 2 times", "3 - 4 times", "5 - 6 times", "7 times", or "> 7 times".

\section{Spatial analysis using Geographic Information System (GIS)}

The presence of fast-food outlets within 
the $500 \mathrm{~m}, 1000 \mathrm{~m}$ and $1500 \mathrm{~m}$ buffers of the respondent's residence and school was measured using ArcGISTM 10.3 (ESRI, Redland, CA) (Gilliland et al., 2012) in the present study. The current study focused on access to fastfood outlets based on evidence of the associations between fast-food outlet density with unhealthy eating and body weight (He et al., 2012; Kee et al., 2019). Fast-food outlets were defined as franchised restaurants with foods ordered at a counter, paid for in advance with limited service and waiting time, and the foods served are usually big in portion size and prepared following standard procedures. (He et al., 2012; Kee et al., 2019). Respondent's residence address was required for analysing data in GIS. Database of every fast-food outlet in Labuan was obtained from the Food Safety and Quality Division, Labuan Health Department, Ministry of Health Malaysia. Fast-food outlets included in the current study were McDonald's, KFC, Pizza Hut, Marrybrown, SugarBun, Pezzo, Uncle Bob, and Bataras Fried Chicken. On-site environmental audits were performed by the researchers within a $1000 \mathrm{~m}$ buffer around the selected schools during the study to "ground truth" to the accuracy of the database provided. The addresses of respondents' residences, schools, and fast food outlets were converted into geographic coordinates by geocoding service using secondary data (Google earth). The Labuan map was obtained from the Department of Survey and Mapping Malaysia (JUPEM). The addresses of the respondents, fast food outlets, and schools were geocoded using ArcMap ${ }^{\mathrm{TM}}$ tools. The residences and schools of respondents, and fast food outlets were plotted as point features on the map. The $500 \mathrm{~m}, 1000 \mathrm{~m}$ and $1500 \mathrm{~m}$ buffer zones surrounding each residence and school were generated using buffer analysis. The number of fast-food outlets within the buffer zones of residence and school was calculated using GIS point. The location and body weight status of the respondents were displayed on the map using GIS.

\section{Statistical analysis}

Data were analysed using the SPSS version 22.0 (SPSS Inc., Chicago, II, USA) software. All continuous variables were tested for normality. Descriptive statistics were presented as frequency, percentages, mean and SD, while median and interquartile range (IQR) were reported for continuous data if the assumption of normality was not met. Pearson's product-moment correlation coefficient or Spearman's rho was used to assess the correlation between two continuous variables. Independent sample $t$-test was used to test for a statistically significant difference between two independent sample means. One-way analysis of variance (ANOVA) test was used to test for statistical difference between more than two independent sample means. The significance of the tests was set at $p<0.05$. Variables found to have an association with BAZ in simple linear regression at a level of significance of 0.25 were further analysed through multiple linear regression. Multiple linear regression with the stepwise variable selection method was performed to determine the contribution of each variable towards body weight status (BAZ) at a significance level of $p<0.05$.

\section{RESULTS}

Socio-demographic characteristics, eating behaviours, parent's purchases of fast food for family meals, availability of neighbourhood fastfood outlets and body weight status (BAZ)

A total of 437 participants agreed to take part, but 17 respondents had incomplete 
anthropometric data or did not complete the questionnaires. Hence, they were excluded from the analysis, resulting in a final sample size of 420 respondents. Thus, the response rate was $87.3 \%$. The socio-demographic characteristics, eating behaviours, parent's purchases of fast food for family meals, availability of neighbourhood fast-food outlets, and body weight status (BAZ) of respondents are presented in Table 1. A total of 420 adolescents were involved in the present study (male: $32.6 \%$, female: $67.4 \%$ ). Mean age of the respondents was $14.4 \pm 1.2$ years old. A majority of the respondents were Malays (55.0\%), followed by Bumiputra Sabah (29.0\%), Chinese (9.0\%), Bumiputra Sarawak

Table 1. Socio-demographic characteristics, eating behaviours, parent's purchases of fast food for family meals, neighbourhood fast-food outlets availability and body weight status (BAZ) of the respondents $(n=420)$

\begin{tabular}{|c|c|c|c|}
\hline & $n$ & $\%$ & $\begin{array}{c}\text { Mean } \pm S D / \\
\text { Median }(I Q R)^{n}\end{array}$ \\
\hline \multicolumn{4}{|l|}{ Socio-demographic characteristics } \\
\hline \multicolumn{4}{|l|}{ Sex } \\
\hline Male & 137 & 32.6 & \\
\hline Female & 283 & 67.4 & \\
\hline Age (year) & & & $14.4 \pm 1.2$ \\
\hline \multicolumn{4}{|l|}{ Ethnicity } \\
\hline Malay & 231 & 55.0 & \\
\hline Chinese & 38 & 9.0 & \\
\hline Bumiputra Sabah & 122 & 29.0 & \\
\hline Bumiputra Sarawak & 17 & 4.0 & \\
\hline Other ethnicities & 12 & 3.0 & \\
\hline \multicolumn{4}{|l|}{${ }^{+}$School area } \\
\hline Urban & 186 & 44.3 & \\
\hline Rural & 234 & 55.7 & \\
\hline${ }^{\ddagger}$ Household income level ${ }^{\S}(\mathrm{RM})(n=410)$ & & & $2000(2885)$ \\
\hline Low (B40: < RM3860) & 293 & 71.5 & \\
\hline Moderate (M40: RM3860- RM8319) & 88 & 21.5 & \\
\hline High (T20: > RM8319) & 29 & 7.0 & \\
\hline \multicolumn{4}{|l|}{ Father's education level ${ }^{\S}(n=376)$} \\
\hline University/ Pre-university & 76 & 20.2 & \\
\hline Secondary school & 226 & 60.1 & \\
\hline Primary school & 47 & 12.5 & \\
\hline No formal education & 27 & 7.2 & \\
\hline \multicolumn{4}{|l|}{ Mother's education level ${ }^{\S}(n=402)$} \\
\hline University/ Pre-university & 85 & 21.1 & \\
\hline Secondary school & 231 & 57.5 & \\
\hline Primary school & 58 & 14.4 & \\
\hline No formal education & 28 & 7.0 & \\
\hline \multicolumn{4}{|l|}{ Eating behaviours (days/week) } \\
\hline Frequency of eating outside of home & & & $1.9 \pm 1.5$ \\
\hline Frequency of eating at western fast-food restaurant & & & $1.5 \pm 1.4$ \\
\hline Frequency of buying takeaway/delivery western fast food & & & $1.4 \pm 1.6$ \\
\hline
\end{tabular}


Table 1. Socio-demographic characteristics, eating behaviours, parent's purchases of fast food for family meals, neighbourhood fast-food outlets availability and body weight status (BAZ) of the respondents $(n=420)$ [Cont'd]

\begin{tabular}{|c|c|c|c|}
\hline & $n$ & $\%$ & $\begin{array}{c}\text { Mean } \pm S D / \\
\text { Median }(I Q R)\end{array}$ \\
\hline Parent's purchases of fast food for family meals & & & $2.0(1.0)^{\pi}$ \\
\hline Never & 127 & 30.2 & \\
\hline $1-2$ times/week & 250 & 59.5 & \\
\hline 3-4 times/week & 37 & 8.8 & \\
\hline 5-6 times/week & 2 & 0.5 & \\
\hline 7 times or more/week & 4 & 1.0 & \\
\hline \multicolumn{4}{|l|}{ Availability of fast-food outlets } \\
\hline \multicolumn{4}{|l|}{ Number of fast-food outlets nearby home } \\
\hline $500 \mathrm{~m}$ buffer & & & $0(0)^{\top}$ \\
\hline 0 & 400 & 95.2 & \\
\hline$\geq 1$ & 20 & 4.8 & \\
\hline $1000 \mathrm{~m}$ buffer & & & $0(0)^{\top}$ \\
\hline 0 & 358 & 85.2 & \\
\hline$\geq 1$ & 62 & 14.8 & \\
\hline $1500 \mathrm{~m}$ buffer & & & $0(0)^{\top}$ \\
\hline 0 & 332 & 79.0 & \\
\hline$\geq 1$ & 88 & 21.0 & \\
\hline \multicolumn{4}{|l|}{ Number of fast-food outlets nearby school } \\
\hline $500 \mathrm{~m}$ buffer & & & - \\
\hline 0 & 420 & 100.0 & \\
\hline$\geq 1$ & 0 & 0 & \\
\hline $1000 \mathrm{~m}$ buffer & & & $2.7 \pm 3.0$ \\
\hline 0 & 234 & 55.7 & \\
\hline$\geq 1$ & 186 & 44.3 & \\
\hline $1500 \mathrm{~m}$ buffer & & & $4.9 \pm 5.5$ \\
\hline 0 & 234 & 55.7 & \\
\hline$\geq 1$ & 186 & 44.3 & \\
\hline Body weight status (BMI-for-age, BAZ) & & & $0.36 \pm 1.46$ \\
\hline Severe thinness & 3 & 0.7 & \\
\hline Thinness & 13 & 3.1 & \\
\hline Normal & 265 & 63.1 & \\
\hline Overweight & 74 & 17.6 & \\
\hline Obesity & 65 & 15.5 & \\
\hline
\end{tabular}

${ }^{\dagger}$ Based on Labuan Corporation (2019)

*Based on Department of Statistic, Malaysia (2017)

${ }^{\S}$ Missing data on socio-demographic characteristics of parents

"Median (IQR)

$(4.0 \%)$ and other ethnic groups (3.0\%). About half of the respondents' mother (56.0\%) participated in this study. About two-thirds of the respondents' fathers (60.1\%) and mothers (57.5\%) had completed secondary school education, while approximately onefifth of the respondents' fathers $(20.2 \%)$ and mothers $(21.1 \%)$ completed tertiary education. Most of the respondents were from a low household income family $(71.5 \%)$, with a median monthly 


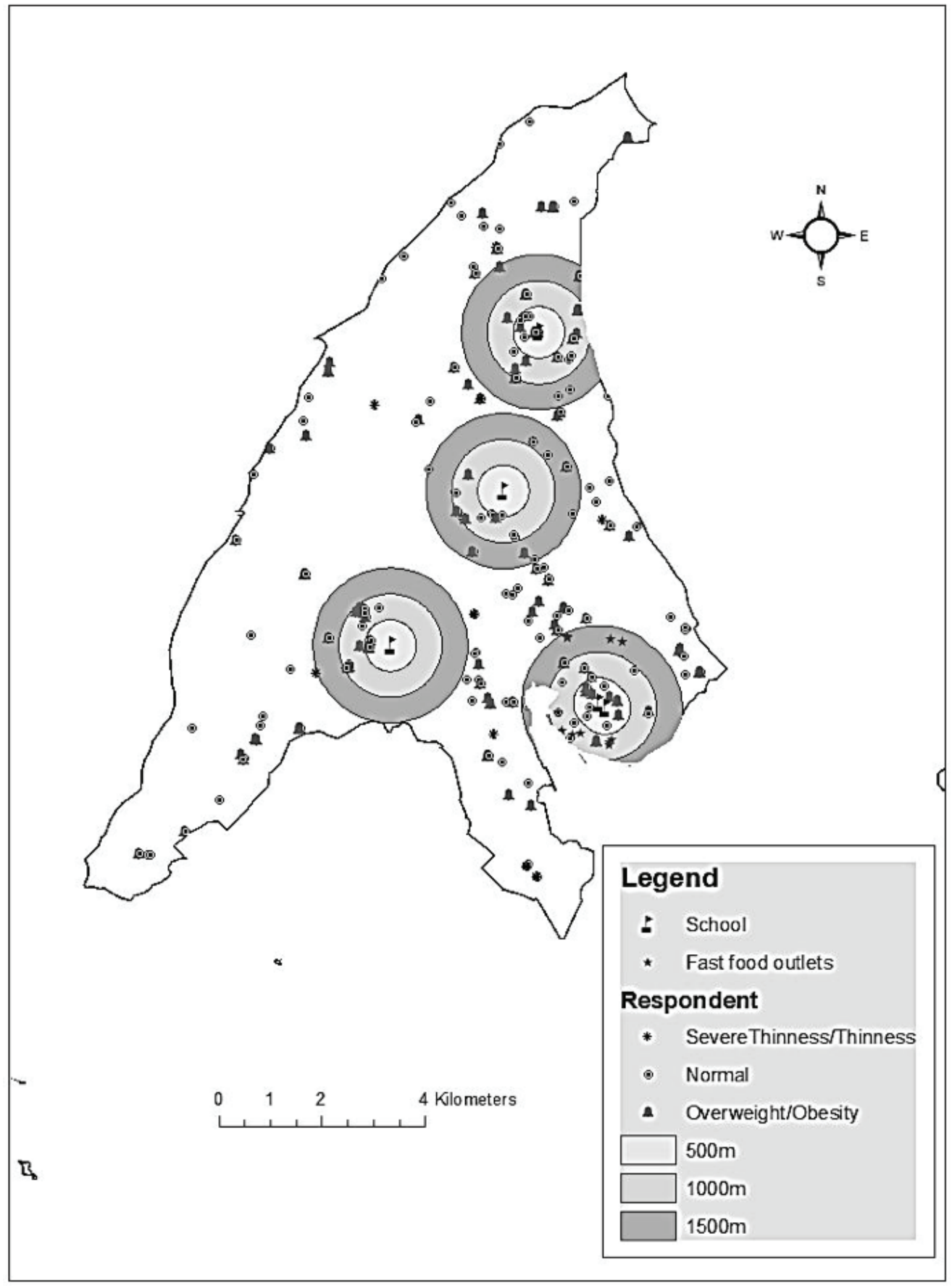

Figure 1. Distribution of fast-food outlets, schools and residences of respondents by body weight status in the Federal Territory of Labuan 
household income of RM2000. The mean for the frequency of eating outside of home, frequency of eating at western fast-food restaurants, and buying takeaway or delivery western fast food were $1.9 \pm 1.5$ days/week, $1.5 \pm 1.4$ days/week and $1.4 \pm 1.6$ days/week, respectively. A total of $59.5 \%$ parents purchased fast food as their family meals for 1 to 2 times a week. Based on the WHO Growth Reference 2007, a majority of the respondents had normal weight (63.1\%), followed by overweight $(17.6 \%)$, obesity (15.5\%), thinness (3.1\%), and severe thinness $(0.7 \%)$, with a mean BAZ of $0.36 \pm 1.46$.

Figure 1 shows the distribution of fast-food outlets, schools and residences of the respondents by body weight status, which was conducted using GIS. The availability of fast-food outlets within the $500 \mathrm{~m}, 1000 \mathrm{~m}$ and $1500 \mathrm{~m}$

Table 2. Associations of socio-demographic factors, eating behaviours, parent's purchases of fast food for family meals and availability of fast-food outlets with BAZ $(n=420)$

\begin{tabular}{|c|c|c|c|}
\hline Factors & Mean $\pm S D(B A Z)$ & $r / t / F$ & $p$ \\
\hline Sex ${ }^{a}$ & & -1.30 & 0.19 \\
\hline Male & $0.22 \pm 1.61$ & & \\
\hline Female & $0.42 \pm 1.38$ & & \\
\hline Ethnicity ${ }^{\mathrm{b}}$ & & 0.52 & 0.72 \\
\hline Malay & $0.43 \pm 1.50$ & & \\
\hline Chinese & $0.21 \pm 1.57$ & & \\
\hline Bumiputra Sabah & $0.31 \pm 1.44$ & & \\
\hline Bumiputra Sarawak & $0.38 \pm 1.12$ & & \\
\hline Other ethnicities & $-0.07 \pm 1.10$ & & \\
\hline Monthly household income ${ }^{c}$ & & 0.12 & $0.02 *$ \\
\hline \multicolumn{4}{|l|}{ Eating behaviours } \\
\hline Frequency of eating outside of home ${ }^{d}$ & & 0.03 & 0.60 \\
\hline Frequency of eating at western fast-food restaurant ${ }^{d}$ & & -0.04 & 0.46 \\
\hline Frequency of buying takeaway/delivery fast food ${ }^{d}$ & & -0.04 & 0.46 \\
\hline Parent's purchases of fast food for family meals ${ }^{c}$ & & -0.11 & $0.03 *$ \\
\hline \multicolumn{4}{|l|}{ Number of fast-food outlets nearby home ${ }^{c}$} \\
\hline within $500 \mathrm{~m}$ buffer & & 0.01 & 0.79 \\
\hline within $1000 \mathrm{~m}$ buffer & & 0.01 & 0.89 \\
\hline within $1500 \mathrm{~m}$ buffer & & 0.06 & 0.22 \\
\hline \multicolumn{4}{|l|}{ Number of fast-food outlets nearby school ${ }^{\mathrm{d}}$} \\
\hline within $1000 \mathrm{~m}$ buffer & & 0.06 & 0.19 \\
\hline within $1500 \mathrm{~m}$ buffer & & 0.06 & 0.19 \\
\hline
\end{tabular}

${ }^{*} p<0.05$

${ }^{a}$ Independent-sample $t$-test was used for comparing BAZ between males and females;

${ }^{\mathrm{b}}$ One-way ANOVA test was used for comparing BAZ between Malay, Chinese, Bumiputra Sabah, Bumiputra Sarawak and other ethnicities;

${ }^{\mathrm{c}}$ Spearman Rho Correlation test was used for assessing the correlations between monthly household income, number of fast-food outlets nearby home and parent's purchases of fast food for family meals with BAZ;

${ }^{\mathrm{d}}$ Pearson Correlation test was used for assessing the correlations between frequency of eating outside of home, frequency of eating at western fast-food restaurant and number of fast-food outlets nearby school with BAZ 
Table 3. Simple and multiple linear regression analyses using BAZ as dependent variable

\begin{tabular}{|c|c|c|c|c|c|c|}
\hline \multirow[t]{2}{*}{ Factors } & \multicolumn{3}{|c|}{ Simple linear regression } & \multicolumn{3}{|c|}{ Multiple linear regression } \\
\hline & 8 & $95 \% C I$ & $p$ & 8 & $95 \% C I$ & $p$ \\
\hline \multicolumn{7}{|l|}{$\operatorname{Sex}^{+}$} \\
\hline Female & 0.20 & $-0.10,0.50$ & $0.19 *$ & & & \\
\hline \multicolumn{7}{|l|}{ Ethnicity $^{+}$} \\
\hline Chinese & -0.21 & $-0.72,0.29$ & 0.41 & & & \\
\hline Bumiputra Sabah & -0.12 & $-0.44,0.20$ & 0.47 & & & \\
\hline Bumiputra Sarawak & -0.05 & $-0.77,0.67$ & 0.89 & & & \\
\hline Other ethnicities & -0.50 & $-1.35,0.35$ & $0.25^{*}$ & & & \\
\hline \multicolumn{7}{|l|}{ Eating behaviours } \\
\hline $\begin{array}{l}\text { Frequency of eating } \\
\text { outside of home }\end{array}$ & 0.03 & $-0.07,0.12$ & 0.60 & & & \\
\hline $\begin{array}{l}\text { Frequency of eating at } \\
\text { western fast-food } \\
\text { restaurant }\end{array}$ & -0.04 & $-0.13,0.06$ & 0.46 & & & \\
\hline $\begin{array}{l}\text { Frequency of buying } \\
\text { takeaway/ delivery fast } \\
\text { food }\end{array}$ & -0.03 & $-0.12,0.06$ & 0.46 & & & \\
\hline $\begin{array}{l}\text { Parent's purchases of fast } \\
\text { food for family meals }{ }^{c}\end{array}$ & -0.25 & $-0.45 .-0.04$ & $0.02^{*}$ & -0.25 & $-0.45,-0.04$ & $0.02^{* *}$ \\
\hline $\begin{array}{l}\text { Number of fast-food } \\
\text { outlets nearby school } \\
\text { within the } 1000 \mathrm{~m} \text { buffer }\end{array}$ & 0.03 & $-0.02,0.08$ & $0.19 *$ & & & \\
\hline $\begin{array}{l}\text { Number of fast-food } \\
\text { outlets nearby school } \\
\text { within the } 1500 \mathrm{~m} \text { buffer }\end{array}$ & 0.02 & $-0.01,0.04$ & $0.19 *$ & & & \\
\hline \multicolumn{7}{|c|}{$\begin{array}{l}\beta=\text { Unstandardised Regression, } \mathrm{CI}=\text { Confidence Interval } \\
{ }^{\circ} \text { Reference categories were male and Malay }\end{array}$} \\
\hline \multicolumn{7}{|c|}{ * $p<0.25$} \\
\hline \multicolumn{7}{|c|}{$\begin{array}{l}{ }^{*} p<0.05, F(1,419)=5.585, \text { sig- } F=0.019, R=0.115, R^{2}=0.013 \\
\text { Stepwise method was used for variable selection in multiple linear regression; } \\
\text { Homoscedasticity, normality and linearity of the model were checked and model assumptions } \\
\text { were met }\end{array}$} \\
\hline
\end{tabular}

buffers around respondents' schools was demonstrated (Figure 1). The presence of fast-food outlets was in the town area of Labuan. As shown in Table 1, most of the respondents did not have any fastfood outlets present within the $500 \mathrm{~m}$ (95.2\%), 1000m (85.2\%), and $1500 \mathrm{~m}$ $(79.9 \%)$ buffers around their residences. All respondents (100\%) had no fast-food outlets within the $500 \mathrm{~m}$ buffer around their schools. However, almost half of the respondents $(44.3 \%)$ had at least one fast-food outlet within the $1000 \mathrm{~m}$ and $1500 \mathrm{~m}$ buffers around their schools. The mean total number of fast-food outlets within the $1000 \mathrm{~m}$ and $1500 \mathrm{~m}$ buffers around their schools were three and five, respectively. 


\section{Associations of socio-demographic factors, eating behaviours, parent's purchases of fast food for family meals and availability of neighbourhood fast-food outlets with BAZ}

Table 2 shows the associations of sociodemographic factors, eating behaviours, parent's purchases of fast food for family meals, and availability of neighbourhood fast-food outlets with BAZ of the respondents. There was a statistically significant, positive correlation between household income and BAZ of the respondents $\quad\left(r_{s}=0.121, \quad p=0.015\right)$. Parent's purchases of fast food for family meals was statistically negatively correlated with BAZ of the respondents $\left(r_{s}=-0.107, p=0.029\right)$. There were no statistically significant associations between sex, ethnicity, frequency of eating outside of home, frequency of eating at western fast-food restaurants, frequency of buying takeaway or delivery fast foods, and availability of fast-food outlets within the $500 \mathrm{~m}, 1000 \mathrm{~m}$ and $1500 \mathrm{~m}$ buffers around residences or schools with BAZ of the respondents $(p>0.05)$.

\section{Contributions of socio-demographic factors, eating behaviours, parent's purchases of fast food for family meals and availability of neighbourhood fast-food outlets with BAZ}

Table 3 shows the simple and multiple linear regressions of socio-demographic factors, eating behaviours, parent's purchases of fast food for family meals, and availability of neighbourhood fastfood outlets with BAZ of the respondents. Variables tested in the simple linear regression with a $p<0.25$ were selected for further analysis in the multiple linear regression. The five variables with $p<0.25$ were sex, ethnicity, parent's purchases of fast food for family meals, availability of fast-food outlets within the $1000 \mathrm{~m}$ and $1500 \mathrm{~m}$ buffers of school. Multiple linear regression showed that less parent's purchases of fast food for family meals statistically significantly contributed towards higher BAZ in the respondents $(b=-0.246,95 \% \mathrm{CI}=-0.440$, $-0.041, p=0.019)$, which explained a total of $1.3 \%$ of the variances in BAZ of the respondents at 0.05 level of significance.

\section{DISCUSSION}

In the present study, the prevalence of overweight and obesity (33.1\%) was ten times higher than the prevalence of thinness and severe thinness (3.8\%) among adolescents aged 12 to 16 years. The high prevalence of overweight and obesity among adolescents in Labuan indicated that obesity intervention programme was necessary. The present study was consistent with the prevalence of overweight and obesity among adolescents in the nationwide Adolescents Nutrition Survey Malaysia 2017 (33.7\%). Additionally, the prevalence of overweight and obesity in the present study was higher than the prevalence of overweight and obesity reported in China $(24.3 \%)$ between the years 2011 and 2015 (Zhang et al., 2018). However, the study in China used the International Obesity Task Force (IOTF) classification, while the current study used the WHO Growth Reference (2007). Different cut-off points for the classification of body weight status may have led to different results in the prevalence of overweight and obesity. The WHO reference could have overestimated the prevalence of overweight and obesity among adolescents compared with the IOTF references (Banjade, Naik \& Narasannavar, 2015).

The current study found that the majority of respondents were from low household income families (<RM3860/ month). The current study showed that higher monthly household income 
was associated with higher BAZ of the respondents. This indicated that $\mathrm{BAZ}$ of the adolescents was dependent on household income. The adolescents who came from higher income families were more likely to enjoy eating at western style fast-food restaurants as compared to those from lower income families (Aloia et al., 2013). In addition, higher household income is associated with food choices and increased purchasing of fast foods (Thornton, Bentley \& Kavanagh, 2011). In the current study, the adolescents from higher income families had higher body weight as they might have received more pocket money from their parents to eat at hawker stalls or local restaurants, buying takeaway western fast foods, and eating at western fast-food restaurants.

The present study showed that there was no significant difference in BMI-for-age by sex, whereby the finding was similar with a previous study among early adolescents in Hulu Langat District, Selangor (Woon, Chin \& Mohd Nasir, 2015). However, the current finding was inconsistent with previous studies (Aryati et al., 2017; IPH, 2015; IPH, 2017; Lai et al., 2015). For instance, a study among adolescents aged 13 to 17 years by Aryati et al. (2017) reported that body weight status was significantly higher in females as compared to males in Terengganu. In contrast, nationwide studies reported the prevalence of overweight and obesity to be higher in male adolescents compared to female adolescents (IPH 2013; IPH 2017). A previous study among Malaysian adolescents living in day-school hostels found that sex was significantly associated with thinness, but not overweight in adolescents (Lai et al., 2015). However, a previous study by Lai et al. (2015) was not comparable with the current study as the study subjects in the current study were from day-schools, in which their dietary behaviours may differ from adolescents living in day-school hostels as indicated by Lai et al. (2015).

The present study showed that less parent's purchases of fast food for family meals was associated with higher BAZ of the adolescents, which was inconsistent with a previous study, whereby parent's purchases of fast food for family meals was not associated with adolescents' BMI (Boutelle et al., 2007). Besides, the previous study also indicated that parent's purchases of fast food was associated with increased consumption of salty snack foods and decreased consumption of vegetables (Boutelle et al., 2007). The higher frequency of taking fast foods may increase the risk of obesity during adulthood when energy needs are reduced (French et al., 2007). In addition, a previous study found that parents with overweight or obese children were less likely to pressure their children to finish all the foods (Leiu \& Chin, 2019). Therefore, we hypothesised that parents with higher body weight adolescents in the current study were more concerned about their child's body weight, hence restricted their fast food intake and reduced the purchasing of fast food for family meals to manage their children's body weight during the study period.

The present study also found that less purchases of fast food for family meals contributed towards higher BAZ of the adolescents. The present study could explain $1.3 \%$ of the variances in BAZ of the respondents as only one variable was retained in the final model. $R^{2}$ value was low in the present study as there is a possibility that some risk factors were not measured in the study such as physical activity, body image perception, energy expenditure and energy intake. Therefore, further study is suggested to include energy intake, physical activity, energy expenditure, body image perception, home environment and 
physical environment factors in the study.

The present study found that eating behaviours such as the frequency of eating at western fast-food restaurants and buying take away or delivery fast foods was not significantly associated with BAZ of the adolescents, inconsistent with a previous study (Braithwaite et al., 2014), which reported that frequent consumption of fast foods increased the risk of overweight and obesity. On the other hand, the present study was consistent with other previous studies (French et al., 2007; IPH, 2013). French et al. (2007) found that the frequency of taking fast food was associated with male adolescents, but not female adolescents. However, in this current study, majority of the respondents were females. Another possible explanation is that adolescents are experiencing growth and therefore higher energy intake is needed. With that, we hypothesised that adolescents' body weight was less influenced by high caloric foods, either eaten at local food stalls or western fastfood restaurants. Besides, a previous study indicated that early adolescents aged 10 to 11 years old with higher body weight had lower energy intake (Woon, Chin \& Mohd Nasir, 2015). Previous study found that majority of adolescents who correctly perceived themselves to be overweight and obese had the intention to lose weight (IPH, 2017). Therefore, we hypothesised that respondents with higher body weight were dissatisfied with their body size and consequently restricted their food intakes during the study period.

The current findings indicated no association between the availability of fast-food outlets around residences and schools with BAZ of respondents, which was consistent with previous studies (Berge et al., 2014; Kelly et al., 2019). For instance, a study by Berge et al. (2014) among 2682 adolescents with a mean age of 14.5 years indicated that high density of fast-food outlets within $1600 \mathrm{~m}$ of home and fast-food outlets within $1200 \mathrm{~m}$ were not significantly associated with BAZ of adolescents. This could be explained by previous evidence indicating no associations found between fast-food outlets around schools with consumption of soft drink, sweets and chips (Kelly et al., 2019). However, the current finding was inconsistent with Kee et al. (2019), which reported that the availability of fast-food outlets within a $1000 \mathrm{~m}$ radius of residences was significantly associated with being overweight among children aged 5 to 18 years. The inconsistent finding of the current study could be due to the greater percentage of respondents who had no fast-food outlets present around their residences and schools. Previous studies (He et al., 2012; Virtanen et al., 2015) were conducted in urban environments that consisted of high density fast-food outlets, whereas the current study consisted of low density fast-food outlets. Besides, the students with higher household income levels in the current study were buying more foods at hawker centres, coffee shops, or food stalls, as well as buying takeaway or delivery fast foods instead of eating at their neighbourhood fast-food outlets. Therefore, the current study was unable to show significant associations between the availability of neighbourhood fastfood outlets around residences and schools with BAZ of the adolescents.

There were several limitations in the study. The cross-sectional design in this study was unable to determine the causal relationship between risk factors and BAZ. Additionally, the number of male and female respondents in the current study was not equally distributed, whereby female respondents were higher compared with male respondents that could have affected the results of the study. Another limitation of this study 
was the lack of information on energy intake, types of foods purchased, and physical activity, which might have been important factors that contributed to BAZ of the adolescents. Furthermore, the outcome of this study is not guaranteed to be representative of the adolescents and parents in Malaysia due to its sampling design. However, the findings gave important information on body weight status and the associations between factors and body weight status (BMI-for-age) among adolescents in Labuan. The study was also able to demonstrate the distribution of fast-food outlets and residences of respondents by body weight status on a map.

\section{CONCLUSION}

The current study showed that the prevalence of overweight and obesity was higher than the prevalence of thinness and severe thinness among adolescents in the Federal Territory of Labuan. Higher household income and less parent's purchases of fast food for family meals were associated with higher BAZ among the adolescents in Labuan. The multiple linear regression indicated that less parent's purchases of fast food for family meals significantly contributed towards higher BAZ of the respondents. Therefore, appropriate intervention programmes need to be taken, focusing on adolescents and their parents from middle and high household income families to address the obesity problem in the population. Although the current study reported that the availability of fast-food outlets and frequency of taking fast foods were not associated with BAZ of the adolescents, intervention programmes should still focus on promoting healthy menu and healthy cooking in restaurants and school canteens to create a healthier food environment so that adolescents can have access to healthier food choices. Parents play an important role in helping their children to practise healthy eating and maintain a healthy body weight. Parents who were concerned about their children's body weight should encourage their children to practise good eating habits, reduce purchasing of high caloric foods in restaurants or fast-food outlets and prepare healthy meals for the family frequently. The present study also found that the study variables explained $1.3 \%$ of the variances in $\mathrm{BAZ}$ of the adolescents. This indicated that other variables that were not measured in the study also contributed to the variances of $B A Z$ of the adolescents. Therefore, other factors such as behavioural factors, family and environmental factors, physical activity, physical environment, and nutrition knowledge should be considered in future studies to determine their potential effects on BAZ of adolescents.

\section{Acknowledgements}

The authors would like to express their appreciation towards all parties involved in the present study including the Ministry of Education Malaysia, State Education Department of Labuan, State Health Department of Labuan and Universiti Putra Malaysia. We also wish to express our gratitude to all the principals, school administrators, teachers, enumerators, and all the respondents for their participation and cooperation throughout the study period.

\section{Authors' contributions}

HSF, designed the study, conducted the study, data analysis and interpretation, and prepared the draft of the manuscript; CYS, principal investigator, designed the study, led the study, advised on data analysis and interpretation, and reviewed the manuscript; ARMS, designed the study, advised on analysis using GIS and reviewed the manuscript; LPY, designed the study, advised on data analysis and interpretation, and reviewed the manuscript.

\section{Conflict of interest}

The authors declare that there is no conflict of interest. 


\section{References}

Aday LA, \& Cornelius LJ (2006). Designing and Conducting Health Surveys: A Comprehensive Guide, Third Edition. Jossey-Bass, San Francisco, United States of America.

Aloia CR, Gasevic D, Yusuf S, Teo K, Chockalingam A, Patro BK, Kumar R, \& Lear SA. (2013). Differences in perceptions and fast food eating behaviours between Indians living in high- and low-income neighbourhoods of Chandigarh, India. Nutr $J$ 12(4). https://doi. org/10.1186/1475-2891-12-4

Aryati A, Nurzaime Z, Nor Saidah AM, Mohd Razif S, Syed Saadun Tarek Wafa SSTW, Rahmah MA, Engku Fadzli Hasan AS, Ahmed, A (2017). Body weight status of school adolescents in Terengganu, Malaysia: a population baseline study. BMC Public Health 17(1):9.

Atay Z, \& Bereket A (2016). Current status on obesity in childhood and adolescence: Prevalence, etiology, co-morbidities and management. Obes Med 3:1-9. https://doi. org/10.1016/j.obmed.2016.05.005

Banjade B, Naik, VA, \& Narasannavar A (2015). Comparison of CDC, WHO and IOTF growth references in relation to overweight and obesity in college adolescents of North Karnataka, India. Al Ameen J Med Sci 8(1):72-76.

Berge JM, Wall M, Larson N, Forsyth A, Bauer KW, \& Neumark-Sztainer D (2014). Youth dietary intake and weight status: Healthful neighborhood food environments enhance the protective role of supportive family home environments. Health Place 26:69-77.

Boutelle KN, Fulkerson JA, Neumark-Sztainer D, Story M \& French SA (2007). Fast food for family meals: relationships with parent and adolescent food intake, home food availability and weight status. Public Health Nutr 10(01):16-23.

Braithwaite I, Stewart AW, Hancox RJ, Beasley R, Murphy R \& Mitchell EA (2014). Fast-food consumption and body mass index in children and adolescents: an international crosssectional study. BMJ Open 4(12):e005813.

Chin YS \& Nasir M (2009). Eating behaviors among female adolescents in Kuantan district, Pahang, Malaysia. Pak J Nutr 8(4):425-432.

DOSM (2017). Current Population Estimates Malaysia 2017. Department of Statistics Malaysia, Putrajaya. From http://www.dosm. gov.my [Retrieved October 30 2017].
Fara Wahida R, Chin YS, Zalilah MS, Barakatun Nisak MS, Sanker K \& Woon FC (2015). Evaluation of diet quality and its associated factors among adolescents in Kuala Lumpur, Malaysia. Nutr Res Pract 9(5):511-516.

Gilliland JA, Rangel CY, Healy MA, Tucker P, Loebach JE, Hess PM, He M, Irwan JD \& Wilk $P$ (2012). Linking childhood obesity to the built environment: a multi-level analysis of home and school neighbourhood factors associated with body mass index. Can $J$ Public Health 103(9):15-21.

He M, Tucker P, Gilliland J, Irwin JD, Larsen K $\&$ Hess P (2012). The influence of local food environments on adolescents' food purchasing behaviors. Int $J$ Environ Res Public Health 9(4):1458-1471.

IPH (2013). The National Health and Morbidity Survey: Malaysia School-Based Nutrition Survey 2012. Institute for Public Health, Ministry of Health Malaysia, Kuala Lumpur.

IPH (2017). National Health and Morbidity Survey (NHMS) 2017: Adolescent Nutrition Survey 2017. Institute for Public Health, Ministry of Health Malaysia, Kuala Lumpur.

Kee CC, Cheong YL, Lim KH, Mohd Ghazali S, Teh CH, Mohd Khairuddin CI, Azli B, Cheong SM, Cheah YK, Noor Aini A \& Ahmad Fauzi Y (2019). Association between Availability of Neighborhood Fast Food Outlets and Overweight Among 5-18 Year-Old Children in Peninsular Malaysia: A Cross-Sectional Study. Int J Environ Res Public Health 16(4). https:/ / doi: 10.3390/ijerph16040593

Kelly C, Callaghan M, Molcho M, Nic Gabhainn S \& Alforque Thomas A (2019). Food environments in and around post-primary schools in Ireland: Associations with youth dietary habits. Appetite 132:182-189. https://doi: 10.1016/j. appet.2018.08.021

Labuan Corporation (2019). Senarai Kampung W.P. Labuan. Labuan: Labuan Corporation. Ministry of Federal Territory Malaysia. From https:// www.pl.gov.my/documents / 10157 /7ccc2ac34550-4e72-9ce8-e2dd27b3c423. [Retrieved May 8 2019].

Lai SC, Chin YS, Chan YM \& Mohd Nasir MT (2015). prevalence of malnutrition and its association with socio-demographic characteristics among Malaysian adolescents living in day-school hostels. Mal J Nutr 21(3):321-334. 
Leiu KH \& Chin YS (2019). Comparison of paternal and maternal feeding practices and parenting styles between healthy weight and overweight or obese primary school children. Mal J Med Health Sci 15(SP1):2-9.

Lytle LA \& Sokol RL (2017). Measures of the food environment: A systematic review of the field, 2007-2015. Health Place 44:18-34. https:// doi.org/10.1016/j.healthplace.2016.12.007

NCD Risk Factor Collaboration (NCD-RisC) (2017). Worldwide trends in body-mass index, underweight, overweight, and obesity from 1975 to 2016: a pooled analysis of 2416 populationbased measurement studies in 128.9 million children, adolescents, and adults. The Lancet 390(10113):2627-2642.

Sahoo K, Sahoo B, Choudhury AK, Sofi NY, Kumar R \& Bhadoria AS (2015). Childhood obesity: causes and consequences. J Family Med Prim Care 4(2):187-192.

Sharifah Intan Zainun SI, Chin YS, Mohd Nasir MT \& Zalilah MS (2020). Malaysian adolescents' perceptions of healthy eating: a qualitative study. Public Health Nutr 9:1-10. https://doi: 10.1017/S1368980019003677

Thornton LE, Bentley RJ \& Kavanagh AM (2011). Individual and area-level socioeconomic associations with fast food purchasing. $J$ Epidemiol Community Health 65(10):873-880.
Virtanen M, Kivimaki H, Ervasti, J, Oksanen, T, Pentti, J, Kouvonen, A, Halonen JI, Kivimaki M, \& Vahtera, J (2015). Fast-food outlets and grocery stores near school and adolescents' eating habits and overweight in Finland. Eur $J$ Public Health 25(4):650-655.

WHO (2009). WHO AnthroPlus for Personal Computers Manual: Software for assessing growth of the world's children and adolescents. World Health Organization, Geneva. From https: / / www.who.int/growthref/tools / who_ anthroplus_manual.pdf [Retrieved 2 December 2 2017].

WHO (2017). Obesity and overweight. World Health Organization, Geneva. From https:/ / www.who.int/news-room/fact-sheets/detail/ obesity-and-overweight [Retrieved October 30 2017].

Woon FC, Chin YS \& Mohd Nasir MT (2015). Association between behavioural factors and BMI-for-age among early adolescents in Hulu Langat district, Selangor, Malaysia. Obes Res Clin Pract 9(4):346-356.

Zhang J, Wang H, Wang Z, Du W, Su C, Zhang J, Jiang H, Jia X, Huang F, Ouyang Y, Wang Y \& Zhang B (2018). Prevalence and stabilizing trends in overweight and obesity among children and adolescents in China, 2011-2015. BMC Public Health 18(1):571. 